\title{
CONCEPÇÕES DE EDUCADORES DE UMA INSTITUIÇÃO DE EDUCAÇÃO PROFISSIONAL TÉCNICA DE NÍVEL MÉDIO SOBRE O CONCEITO DE VIOLÊNCIA ${ }^{1}$ \\ CONCEPTIONS OF TEACHERS FROM A VOCATIONAL-TECHNICAL HIGH SCHOOL ABOUT THE CONCEPT OF VIOLENCE ${ }^{1}$ \\ CONCEPCIONES DE EDUCADORES DE UNA INSTITUCIÓN DE EDUCACIÓN PROFESIONAL TÉCNICA DE NIVEL MEDIO SOBRE EL CONCEPTO DE VIOLENCIA
}

Fernanda Lúcia Maioli*
Alex Sandro Gomes
Pessoa**
Jaqueline Knupp
Medeiros***
Débora Ananias
Guimarães***
Haryadny Kamylla
Macedo Muniz*****

*Assistente Social pelo Centro Universitário Antônio Eufrásio de Toledo de Presidente Prudente e Especialista em Intervenções Psicossociais em contextos de Vulnerabilidade Social na Universidade do Oeste Paulista (Unoeste). Atua como Assistente Social no Centro de Atenção Psicossocial Infantil II (CAPS), vinculado à Prefeitura Municipal de Presidente Prudente. Presidente Prudente, São Paulo, Brasil. E-mail: fernanda.Imaioli@hotmail.com

** Psicólogo pela Unoeste. Licenciado em Educação Física, Mestre e Doutor em Educação pela Universidade Estadual Paulista "Júlio de Mesquita Filho" (Unesp). Realizou estágio de doutorado na Faculdade de Educação e Serviço Social da Universidade de Sydney (Austrália) e Pós-doutorado em Psicologia na Universidade Federal do Rio Grande do Sul (UFRGS). Vinculado ao Departamento de Psicologia e ao Programa de Pós-graduação em Psicologia da Universidade Federal de São Carlos (UFSCar). São Carlos, São Paulo, Brasil. E-mail: alexpessoa@ufscar.br

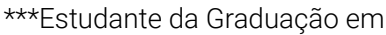
Psicologia da Unoeste e bolsista de Iniciação Científica da Fundação de Amparo à Pesquisa do Estado de São Paulo (Fapesp) (Proc. n. 17/18640-7). Martinópolis, São Paulo, Brasil. E-mail: jaquekmedeiros@gmail.com

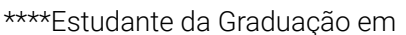
Psicologia da Unoeste. Presidente Prudente, São Paulo, Brasil. E-mail: dgananias@gmail.com

$\star \star \star \star \star \star$ Estudante da Graduação em Psicologia da Unoeste. Presidente Prudente, São Paulo, Brasil. E-mail: haryadnykmuniz@hotmail.com

Recebido para publicação em: 14.11.2017

Aprovado em: 1.6.2018

\section{Resumo}

Este artigo analisou as concepções de educadores de uma instituição de Educação Profissional de Nível Técnico e Profissionalizante acerca da violência. Trata-se de pesquisa quantitativa, de natureza exploratória-descritiva, desenvolvida como estudo de caso. Participaram 76 educadores dos sexos feminino e masculino, de uma instituição localizada em cidade de médio porte no estado de São Paulo. A pesquisa revelou que equívocos marcam a concepção sobre violência dos educadores, sustentada principalmente pela naturalização da violência cometida contra determinados grupos sociais.

Palavras-chave: Concepções. Educadores. Educação Profissional de Nível Técnico e Profissionalizante. Violência. 


\section{Abstract}

This article analyzes the conceptions of teachers from a Vocational-Technical High School about violence. It is quantitative, exploratory-descriptive research, developed as a case study. Participants were 76 female and male teachers from an institution located in a mid-sized city in the state of São Paulo. The research revealed that misconceptions mark the teachers' conception of violence, sustained mainly by the naturalization of violence committed against particular social groups.

Keywords: Conceptions. Teachers. Vocational-Technical Schools. Violence.

\section{Resumen}

Este artículo analiza las concepciones de educadores de una institución de Educación Profesional de Nivel Técnico y Profesionalizante acerca de la violencia. Se trata de una investigación cuantitativa, de naturaleza exploratoria-descriptiva, desarrollada como estudio de caso. Participaron 76 educadores de sexo femenino y masculino, de una institución ubicada en una ciudad de medio porte en el estado de São Paulo. El estudio reveló que existen equívocos que marcan la concepción de los educadores sobre la violencia, sustentada principalmente por la naturalización de la violencia cometida contra determinados grupos sociales.

Palabras clave: Concepciones. Educadores. Educación Profesional de Nivel Técnico y Profesionalizante. Violencia.

\section{Introdução}

A violência, de uma forma geral, é um tema muito debatido na sociedade. A mídia impressa, falada e visual, inclusive as redes sociais, são grandes difusores de ideias sobre o tema. Contudo, como os educadores ${ }^{1}$ dos diferentes níveis de ensino entendem a violência? Qual conhecimento é necessário para lidar com a questão? A atuação desses profissionais é de relevância para a quebra dos ciclos da violência?

Para a compreensão da violência como um fenômeno multifacetado, faz-se necessária a elaboração de um modelo explicativo de suas categorias, como atinge o ambiente escolar e o cotidiano das comunidades educativas (alunos, familiares de alunos, docentes e demais profissionais).

Sabe-se que a violência é um fenômeno de conceituação complexa, multicausal e controversa, que se encontra arraigado nas estruturas sociais, econômicas e políticas (MINAYO, 2009). Sua origem situa-se na correlação assimétrica de força/ poder nos relacionamentos humanos (FALEIROS, 2007). Desse modo, não pode ser entendida de forma unicamente psicológica, como um ato isolado, oriundo do descontrole emocional, de uma patologia ou transtorno, mas sim como o desdobramento das estruturas sociais. 
Fica evidente, dessa forma, que o processo cultural está associado ao fenômeno da violência (ASSIS; NASCIMENTO, 2013; FALEIROS, 1998; MINAYO, 2009). Apesar de ser considerada natural pelo senso comum, a violência não faz parte da natureza do ser humano. Logo, uma pessoa não nasce violenta ou com determinadas características violentas inatas, mas adquire, ao longo da vida, os marcadores sociais que perpetuam essa prática. Aspectos históricos, bem como práticas sociais que legitimam ações de violação de direitos naturalizam e justificam a violência (MARTíN-BARÓ, 1990, 2003).

\section{A educação é uma das bases para transformações e enfrentamento da violência}

Pode-se relacionar as múltiplas dimensões da violência ao aumento dos processos estruturais de exclusão social (SANTOS; TEIXEIRA; RUSSO, 2011), visto que as novas formas de acumulação do capital, de concentração da produção e da tecnologia leva a mudanças sociais e nos padrões convencionais de violência (ADORNO, 2002).

Devido à sua complexidade, reconhece-se que medidas isoladas não resolverão a violência. Ao contrário, ações pontuais apenas masca ram a realidade e não efetivam mudanças substanciais. Assim, necessita-se de mudanças amplas na sociedade como um todo e a educação é uma das bases para transformações e enfrentamento das manifestações de violência (WILLIAMS; STELKO-PEREIRA, 2013).

A comunidade escolar, independentemente do nível de ensino, tem importante papel no tocante à quebra do ciclo da violência (MARANHÃO et al., 2014; MOREIRA; GUZZO, 2017; SANTOS; RODRIGUES, 2013). Nessa perspectiva, o docente passa do papel de especialista de uma determinada disciplina para ocupar a função de um educador consciente do caráter político de sua atuação, o que envolve a compreensão dos problemas sociais. Conteúdos como cidadania, democracia, comunidade, solidariedade e emancipação individual e social devem ser inseridos na formação continuada de docentes e dos demais agentes escolares, com foco na mobilização das instituições educativas para o trabalho com temas transversais, incluindo as formas de manifestação da violência (BRASIL, 2015; SANTOS, 2011).

Cabe à escola e a outras instâncias sociais questionar qual a melhor forma de se combater os indicadores de violência que assolam a sociedade. Trata-se de um ponto de partida para uma intervenção intencional da humanidade a fım da minimização das assimetrias sociais que fazem a violência se perpetuar entre as gerações (SANTOS, 2012; WILLIANS, 2013).

É importante destacar que não está sendo argumentado que a escola deva ser responsabilizada pelo enfrentamento das diversas manifestações de violência. A entrevista conduzida por Pereira e Vieira (2016) com o pesquisador português António Nóvoa mostra que as escolas têm assumido diversas tarefas e acaba ocorrendo um transbordamento de suas funções, repercutindo no excesso de atribuições e no esgotamento psíquico de seus agentes (em especial gestores e docentes). Porém, sem dúvida, é função das instituições educativas criar estratégias de enfrentamento 
à violência em parceria com outras instituições e com as famílias dos estudantes. 0 próprio Ministério da Educação tem elaborado uma série de programas para a mobilização dos espaços educativos no que tange a esta temática (ver, por exemplo, o Programa Escola que Protege $)^{2}$.

espaço

educacional pode

vir a auxiliar

a quebra do

silêncio em torno

da violência

Na construção de uma cultura contra a manifestação das violências, é necessário lidar com temas como discriminações, intolerâncias e exclusões no espaço escolar, identificando as situações em que os seres humanos são tratados como se fossem objetos. Isso é possível a partir de ações colaborativas entre os diferentes atores sociais que compõem a rotina escolar. Assim, o espaço educacional pode vir a auxiliar a quebra do silêncio em torno da violência, quando possibilita o debate aberto com alunos, família, educadores e sociedade (ABRAMOVAY; RUA, 2002; SANTOS, 2012).

Mesmo no interior das instituições educativas de diferentes níveis, uma cultura da violência tem se instaurado, o que tem tornado as pessoas, tanto funcionários como estudantes, reféns dessa lógica perversa (SOARES; MACHADO, 2014). Desse modo, as instituições educativas devem criar ações que problematizem a violência, de modo que todas as pessoas sejam efetivamente engajadas na luta contra a sua manifestação.

A partir disso, torna-se relevante compreender como o tema é tratado nos diferentes níveis de ensino, incluindo no âmbito da Educação Profissional Técnica de Nível Médio. A Lei de Diretrizes e Bases da Educação Nacional (LDB) - Lei n. 9.394/1996 (BRASIL, 2015), complementada pela Lei n. 11.741/2008, traz que esta modalidade de ensino se refere à preparação geral para o trabalho, que deve ocorrer de forma articulada com o ensino médio ou, ainda, subsequente ao mesmo. Pode ser desenvolvida nos próprios estabelecimentos de ensino médio ou em instituições educacionais especializadas, observando os objetivos e as definições que estão contidos nas diretrizes curriculares nacionais.

Contudo, ressalta-se a necessidade de se implementar nos cursos técnicos habilidades que extrapolem apenas a capacidade de aprender uma profissão. A perspectiva de educação defendida pelos proponentes deste artigo sugere uma educação profissional técnica de nível médio diferenciada, no sentido de oferecer uma formação que extrapole o ensino de habilidades voltadas para o mercado de trabalho. Para tanto, é necessário que os educadores desenvolvam habilidades que lhe imprimam competências múltiplas para trabalhar com seus alunos. O grande desafio é a articulação de vários saberes, de caráter científico, filosófico, político, cultural, tecnológico, sociológico, antropológico, entre outros, que estejam apoiados em um ensino que problematize a realidade social e seja significativo, que dê respaldo ao indivíduo na formação de um senso crítico e questionador, que extrapole o conhecimento técnico (SANTOS, 2012; VIAMONTE, 2011). 
Nesse sentido, exige-se do educador um novo perfil. É necessário um profissional/educador reflexivo, que busca uma relação entre prática e teoria de uma forma dialética, capaz de articular os saberes disciplinares, pedagógicos e a experiência profissional, de forma a proporcionar a autonomia e o protagonismo de seus alunos, ensinando-os para a vida (SANTOS, 2012; HEREM, 2009) e, certamente, auxiliando a empreitada de enfrentar a aceitação da perpetuação das diferentes formas pelas quais a violência se manifesta na sociedade.

Com isso, a educação, incluindo o âmbito da Educação Profissional Técnica de Nível Médio, deve levar ao aluno uma visão crítica de homem e de mundo, contextualizada com os problemas atuais e as questões sociais. Deve adotar uma postura intencional, politizada, enfatizando o pensamento sistêmico, que permite a esse aluno transformar sua realidade e o mundo em que está inserido, evitando visões distorcidas de si e dos fatos ao seu redor (MORIN, 2001; SANTOS, 2012).

Ao vislumbrar a interligação entre a violência e o papel da educação, retoma-se que a violência é socialmente construída e seu espectro envolve diferentes formas de manifestação (desde a violência velada, até a agressão física, por exemplo), bem como está presente em todas as camadas sociais. Nesta perspectiva, compreende-se que a educação profissional poderia trazer contribuições em relação à quebra do ciclo da violência, quando se fala na sua nova concepção crítica frente ao mundo, e não apenas de preparar mão de obra para o mercado.

Com base nestas prerrogativas, este artigo tem como finalidade analisar a concepção de educadores de uma instituição de Educação Profissional Técnica de Nível Médio acerca da violência em suas diferentes dimensões.

\section{Método}

De natureza exploratória-descritiva, este estudo foi realizado por intermédio de uma pesquisa de campo, em uma instituição de Educação Profissional Técnica de Nível Médio, localizada em um município de médio porte, no interior do estado de São Paulo, em setembro de 2016. Utilizou-se da abordagem quantitativa, pois esta modalidade de pesquisa possibilita ao pesquisador observar indicadores latentes na realidade posta, sendo possível replicar a pesquisa, por contar com procedimentos controláveis (SEVERINO, 2007; SERAPIONI, 2000).

Uma das vantagens deste tipo de abordagem é que, por se tratar de aplicações em grande escala, o anonimato é garantido, e as pessoas não se sentem intimidadas por conta de suas respostas, dando maior veracidade à pesquisa. Além disso, a violência é um fenômeno que requer uma compreensão sobre a percepção da população, neste caso, educadores, e os significados sociais que a violência tem (MOURA; OLIVEIRA; VASCONCELOS, 2015). 


\subsection{Participantes e instituição}

A amostragem foi intencional e constituiu-se de 76 participantes, em um universo de 106 funcionários. Esses profissionais exercem funções em diferentes setores, como Administração, Atendimento, Biblioteca, Docência, Limpeza e Gerência. Possuem idade que varia entre 21 e 64 anos e nível de escolaridade entre Ensino Fundamental e Superior Completo.

Cabe ressaltar que todos os funcionários da instituição, por serem reconhecidos nesta pesquisa como educadores, foram convidados a participar do estudo. No entanto, devido ao período de férias, ausência nos dias das aplicações ou negativa em responder ao instrumento, foi formado um grupo que passou a ser representativo da amostragem.

Dadas as características do estudo e das estratégias adotadas para constituição amostral, esta investigação se configura como um estudo de caso. Contrariando uma visão corriqueiramente difundida na academia, o estudo de caso não se aplica a casos únicos ou quadros clínicos particulares. De acordo com Yin (2010), o autor de referência para as pesquisas nesse campo investigativo, o estudo de caso pode se constituir a partir de uma análise de uma realidade institucional. Assim, o interesse na investigação se deu a partir de uma unidade específica, com características peculiares que explicam os dados obtidos.

\subsection{Instrumento}

Utilizou-se um questionário adaptado a partir de dois instrumentais (CARDIA, 1999; WILLIAMS; MALDONADO; COSTA, 2008). O instrumento, em sua versão final, possuía 24 (vinte e quatro) afirmações sobre as diferentes expressões de violência voltadas para alguns grupos, a saber: crianças e adolescentes, mulheres, e violência policial. Além disso, os itens permitem a identificação de formas de naturalização e aceitação das expressões da violência por parte dos respondentes.

Todos os funcionários

da instituição, por

serem reconhecidos

nesta pesquisa

como educadores,

foram convidados a

participar do estudo
Cada item do questionário foi apresentado no modelo de escala Likert de 1 (um) a 5 (cinco), cujo número 1 (um) refere-se a "Discordo totalmente" e 5 (cinco) "Concordo totalmente" das respectivas afirmações. Os participantes assinalavam de acordo com suas opiniões, sem que houvesse interferências por parte dos aplicadores. Cabe salientar que nenhum conceito, seja de violência doméstica ou da tipificação da violência, foi explicado aos participantes. Caso isso fosse realizado, poderia implicar a contaminação dos dados. Como os pesquisadores estavam interessados em compreender a concepção dos participantes sobre violência, os mesmos foram orientados a responderem de acordo com suas crenças, sem se preocuparem (naquele momento), se suas respostas estavam certas ou erradas. 
O questionário possui uma estrutura interna, composta por fatores (categorias de análise) controlados exclusivamente pelos pesquisadores. Isto significa que, embora dispersas no instrumento, havia categorias relativas à tipificação da violência, a saber: Naturalização da violência; Violência contra criança e adolescente e bullying; Violência contra a mulher; e Violência policial. O Quadro 1 mostra as categorias, os respectivos itens e o número correspondente no questionário, ou seja, a ordem em que apareciam no instrumento.

\section{Quadro 1- Itens que compuseram o questionário}

\begin{tabular}{|c|c|c|}
\hline Categoria & Afirmações & Item \\
\hline \multirow{7}{*}{$\begin{array}{l}\text { Naturalização da } \\
\text { violência }\end{array}$} & A violência doméstica atinge somente as camadas mais pobres da população. & 3 \\
\hline & É justo eu usar de violência para proteger minha honra. & 9 \\
\hline & $\begin{array}{l}\text { Sentir medo de alguém mais "forte" é normal, aliás, "manda quem pode e } \\
\text { obedece quem tem juízo". }\end{array}$ & 11 \\
\hline & $\begin{array}{l}\text { Não levo desaforo para casa, se alguém me insultar, eu revido na mesma } \\
\text { proporção. }\end{array}$ & 16 \\
\hline & $\begin{array}{l}\text { Em uma escola pública, é justo o professor usar de violência para corrigir um } \\
\text { aluno desobediente. }\end{array}$ & 17 \\
\hline & $\begin{array}{l}\text { Me sinto no direito de insultar outra pessoa quando esta pessoa me agride } \\
\text { também. }\end{array}$ & 20 \\
\hline & Com frequência, é necessário usar a violência para prevenir a violência. & 24 \\
\hline \multirow{7}{*}{$\begin{array}{l}\text { Violência } \\
\text { contra criança } \\
\text { e adolescente e } \\
\text { bullying }\end{array}$} & A criança que cresce em um lar violento torna-se violenta quando crescer. & 1 \\
\hline & Palavras e brincadeiras nunca mataram ninguém. & 4 \\
\hline & $\begin{array}{l}\text { Não é humilhação ou ridicularização chamar o outro por apelidos que ele não } \\
\text { goste, aliás, apelidos não são para gostar mesmo. }\end{array}$ & 7 \\
\hline & $\begin{array}{l}\text { Se cheguei onde estou hoje, foi porque meus pais me deram umas palmadas } \\
\text { quando necessário. }\end{array}$ & 10 \\
\hline & Bullying não existe, vários amigos tiravam "sarro" de mim, e eu sobrevivi. & 13 \\
\hline & Criança que não apanha não aprende. & 21 \\
\hline & Os pais têm o direito de corrigirem os filhos como bem entenderem. & 23 \\
\hline \multirow{5}{*}{$\begin{array}{l}\text { Violência contra } \\
\text { a mulher }\end{array}$} & "Em briga de marido e mulher não se deve meter a colher". & 2 \\
\hline & $\begin{array}{l}\text { Tem mulher que gosta de ser saco de pancadas do marido e só não larga dele } \\
\text { porque não quer. }\end{array}$ & 6 \\
\hline & $\begin{array}{l}\text { Existem mulheres que pedem pra ser abusadas, pois se não quisessem que } \\
\text { mexessem com ela, não usariam roupas tão provocantes. }\end{array}$ & 14 \\
\hline & Existem mulheres que gostam de apanhar. & 18 \\
\hline & $\begin{array}{l}\text { Mulher que apanha também é responsável pelos seus atos, pois "quando um } \\
\text { não quer, dois não brigam". }\end{array}$ & 22 \\
\hline \multirow{5}{*}{ Violência policial } & $\begin{array}{l}\text { A polícia tem direito de revistar pessoas que consideram suspeitas em função } \\
\text { de aparência ou de como se vestem. }\end{array}$ & 5 \\
\hline & Os Direitos Humanos só defendem bandidos. & 8 \\
\hline & A polícia pode torturar um suspeito para obter informações. & 12 \\
\hline & "Bandido bom é bandido morto". & 15 \\
\hline & Se as autoridades falham, nós temos o direito de tomar a justiça em nossas mãos. & 19 \\
\hline
\end{tabular}




\subsection{Procedimentos, análise dos dados e considerações éticas}

O questionário foi aplicado individualmente nas dependências da própria Instituição, sendo assegurada a participação de forma voluntária e sigilosa. Os participantes levaram em média 20 minutos para responder ao questionário e, em geral, não tiveram dúvidas quanto ao preenchimento.

Após o trabalho de campo, os dados coletados passaram por um processo de tabulação e as análises ocorreram por intermédio do software SPSS, versão 21.0, em português. Foram aplicadas técnicas de análises descritivas (média, moda e desvio padrão).

Iniciou-se a pesquisa após aprovação do Comitê de Ética em Pesquisa com Seres Humanos da Universidade do Oeste Paulista - CEP (CAAE: 58668416.4.0000.5515). Todos os participantes assinaram o Termo de Concordância e receberam informações adicionais, quando necessárias. Foi assegurado o sigilo das informações e a omissão de sua identidade em todos os relatórios produzidos.

$\mathrm{Na}$ ocasião da pesquisa de campo, foram coletadas as assinaturas dos participantes no Termo de Consentimento Livre e Esclarecido (TCLE). A pesquisa seguiu todas as orientações da Resolução 466/2012 do Conselho Nacional de Saúde, que versa sobre os parâmetros éticos da pesquisa com seres humanos. O material foi arquivado com a primeira autora e seu orientador e será descartado após cinco anos.

\section{Resultados e discussão}

Os resultados foram organizados em gráficos e retratam dimensões da concepção de violência dos pesquisados. De modo geral, a pesquisa revelou que equívocos marcam a concepção sobre violência dos educadores de nível técnico e profissionalizante, sustentada principalmente pela naturalização da violência e, com mais ênfase, pela banalização da violação dos direitos de crianças, adolescentes e mulheres.

Como explicado na seção Método deste artigo, o questionário foi construído a partir do modelo de escala Likert, o que significa que havia um escalonamento sobre os níveis de concordância para cada afirmativa. Desse modo, quanto mais próxima a resposta da coluna 4 e 5, respectivamente "concordo" e "concordo plenamente", mais indicativos da naturalização ou aceitação da violência foram constatados nas respostas dos participantes.

\subsection{A aceitabilidade das violências na instituição de educação profissional técnica de nível médio}

No Gráfico1, verifica-se a distribuição das respostas dos pesquisados no questionário como um todo. 
Gráfico 1 - Distribuição das respostas em termos dos níveis de concordância com formas de violência

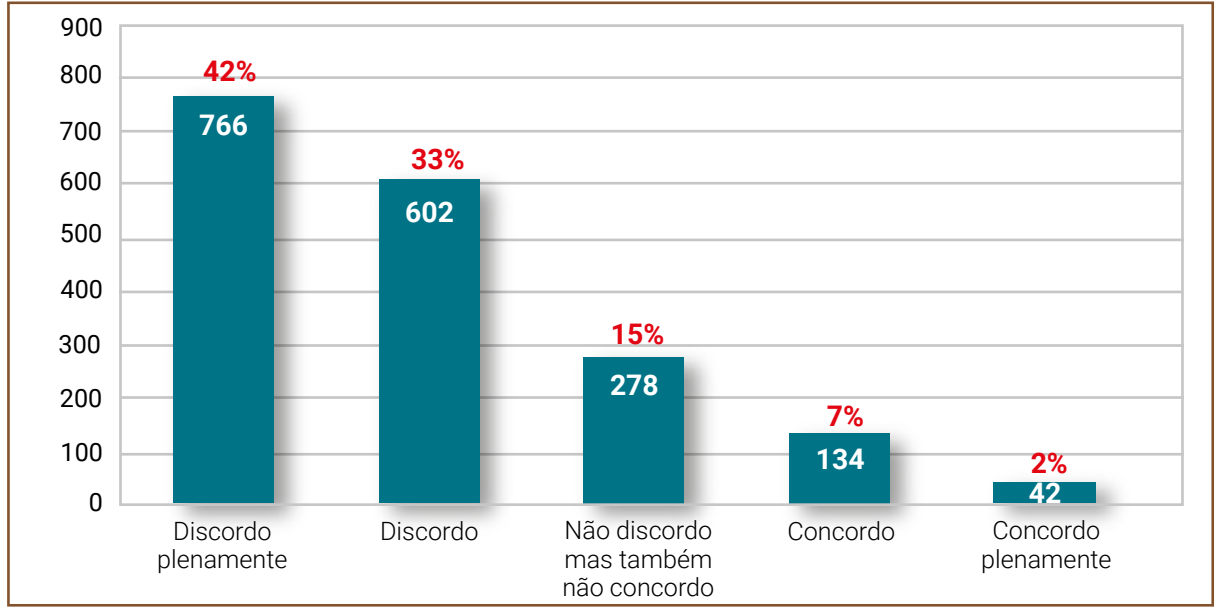

Fonte: Elaborado pelos autores.

No total, foram obtidas 1.822 respostas, pois foram 76 participantes e cada questionário continha 24 itens (não foram considerados dados missings - afirmativas em branco ou com dupla resposta). O dado que chama a atenção é a soma dos itens "Não discordo, mas também não concordo", "Concordo" e "Concordo plenamente", que, juntos, representam 24\% (454 assinalamentos) das respostas. Isso significa que praticamente $1 / 4 / 4$ (um quarto) dos educadores são coniventes, aceitam ou naturalizam algumas expressões da violência.

Alguns dos itens analisados apresentaram um indicador ainda mais elevado. Ao se estabelecer uma linha de corte a partir do ponto central, ou seja, no valor 2,5 (em uma escala que varia entre 1 e 5), três itens apresentam médias mais elevadas: Q1: "A criança que cresce em um lar violento torna-se violenta quando crescer"; Q2: "Em briga de marido e mulher não se deve meter a colher"; Q10: "Se cheguei onde estou hoje, foi porque meus pais me deram umas palmadas quando necessário" (ver Gráfico 2).

\section{Gráfico 2 - Itens com valores mais elevados sobre a aceitação da violência}

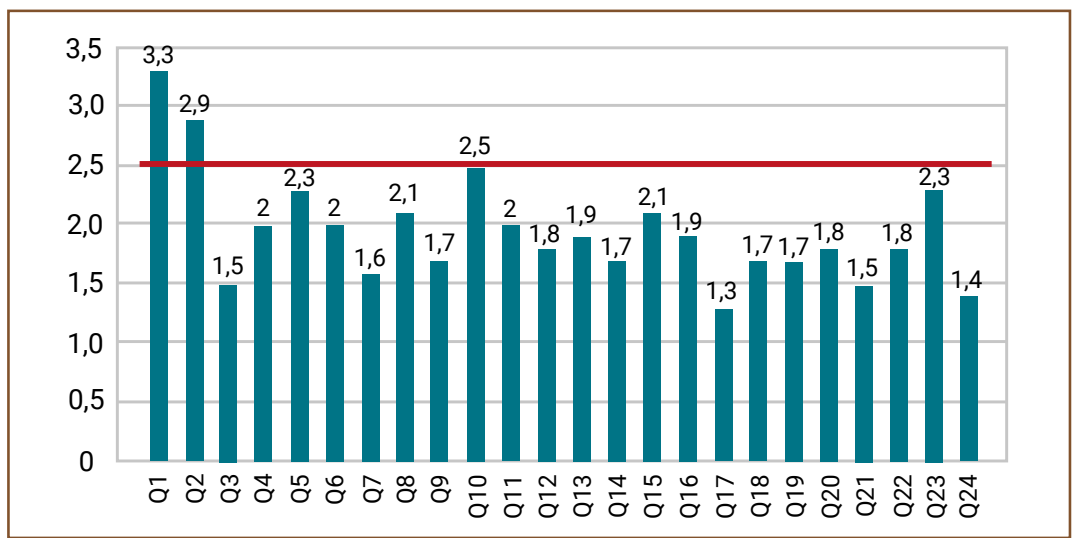

Fonte: Elaborado pelos autores. 
Essas afırmações de certa forma expõem a aceitação de práticas de violência intrafamiliar ou de métodos coercitivos, pois os itens do questionário, especialmente aqueles alusivos a crianças, adolescentes e mulheres, retratam formas de relacionamentos que são permeados por métodos baseados na violência e na destituição dos direitos. Isso ocorre devido à cultura machista e adultocêntrica, que expõe crianças, adolescentes e mulheres a uma condição de subalternidade, a partir do estabelecimento de relações assimétricas de poder (BARUFALDI et al., 2017; D'AFFONSECA; PRIOLO FILHO; WILLIAMS, 2016; HILDEBRAND et al., 2015; RATES et al., 2015).

Os dados a partir do Gráfico 2 também evidenciam contradições nas concepções dos educadores. Houve uma tendência em afirmar que a criança que sofre violência pode se tornar um adulto violento. Paradoxalmente, os mesmos participantes parecem valorizar as práticas coercitivas que receberam de seus cuidadores durante suas próprias infâncias (analisar os itens 1 e 10). A incoerência consiste no fato de haver apologia a práticas coercitivas contra a criança, mesmo levantando como hipótese que as mesmas podem se tornar adultos violentos, caso sejam expostas à violência.

Apesar de ainda ser amplamente aceita pela sociedade e pelas famílias, o que explica as respostas obtidas juntos aos participantes, as palmadas não são consideradas práticas educativas saudáveis. Ao contrário, têm sido apontadas, tanto pelos discursos jurídicos quanto pelas pesquisas científicas (BISCEGLI et al., 2008; BRASIL, 2011; FELTRIN et al., 2013) como práticas educativas tóxicas, que se constituem como formas de violação de direitos dessa população. Autores como Biscegli et al. (2008, p. 369) condenam o uso de palmadas nas práticas educativas:

pela ineficácia da punição corporal, porque não mostra o que deve ser feito e sim o que não deve. Outros autores concordam que a punição apenas enfoca o erro e não há preocupação em ensinar aquilo que é correto [...]. Alguns pesquisadores relatam que, embora a punição corporal possa ser eficaz no instante em que é aplicada, em longo prazo pode acarretar prejuízos não somente para o indivíduo que a recebe, mas também para os outros com quem convive, aumentando os índices de delinqüência, criminalidade e violência contra o cônjuge.

Os castigos físicos e as práticas coercitivas persistem no imaginário social como formas de educação (BRASIL, 2009; COCCO et al., 2010), inclusive de educadores que deveriam militar contrariamente à ocorrência de tais práticas. Patias, Siqueira e Dias (2013) apontam que para o rompimento da naturalização de práticas coercitivas é necessária uma conscientização da população sobre os prejuízos que essas práticas podem trazer à pessoa.

Em um trabalho realizado por Pereira e Williams (2008) sobre a percepção dos educadores de algumas escolas do interior de São Paulo a propósito da violência, constatou-se que $7,8 \%$ dos participantes têm concepções distorcidas sobre a mesma. 
As respostas dadas pelos educadores em tal estudo foram preocupantes, pois indicaram uma distorção e a falta de informação dos profissionais da educação. Os itens que trouxeram mais preocupação aos autores foram os discursos sobre a "falta de cultura" e a "separação dos pais" como causas da violência intrafamiliar. Embora em âmbitos educacionais distintos, em termos do nível das instituições de ensino, constataram-se dados similares, ou seja, a percepção equivocada por parte dos educadores de cursos de nível técnico e profissionalizante sobre violências que ocorrem no âmbito intrafamiliar.

Sabe-se que a violência pode ocorrer em qualquer família, independentemente da classe econômica (MACHADO et al., 2014) e que o divórcio dos pais, muitas vezes, é a melhor forma de enfrentamento da exposição à violência na família (SANTOS; MARIN; CASTOLDI, 2013). Todavia, a presente pesquisa aponta aceitação da violência por educadores, tratando o assunto como algo natural e aceitável. As concepções de família e de relações interpessoais devem, portanto, fazer parte das discussões na formação continuada de educadores de nível técnico e profissionalizante.

Outra pesquisa, realizada por Noronha (2013), investigou a concepção de educadores sobre violência e como eles lidam com o assunto no seu local de trabalho. Participaram da pesquisa seis educadores que tinha formação de ensino médio até pós-graduação. Dentre os educadores, uma das participantes afirmou que palmadas "não matam", pelo contrário, "educam", e que inclusive levou algumas palmadas quando pequena e, hoje, considera-se uma pessoa do bem (dados similares aos encontrados nesta pesquisa). A autora discute que essas concepções de violência contra criança são de origem social e são extremamente difíceis de romper, caracterizando a naturalização da violência em espaços educativos.

Quanto à violência contra a mulher, a questão que aparece com a média mais alta é a de que "em briga de marido e mulher não se mete a colher", ditado popular amplamente propagado no contexto brasileiro, em diversas regiões do país. Essa afirmativa realça que uma sociedade patriarcal e machista sustenta as assimetrias de gênero (CHAUÍ, 2003), bem como evidencia a aceitabilidade que esse tipo de violência tem (GUIMARÃES; PEDROSA, 2015).

Segundo Timm, Pereira e Gontijo (2011), a violência é, por vezes, imperceptível, ocorrendo em cenas de ciúmes que parecem toleráveis. Assim, há uma violência invisível, sutil, difundida pelo patriarcado, pois há uma automatização das agressões físicas e psicológicas.

Pode-se tomar por parâmetro pesquisa realizada por Albuquerque e colaboradoras (2013) no município de João Pessoa (Paraíba), a qual envolveu a participação de 860 mulheres cadastradas em uma Unidade de Saúde da Família. O estudo revelou que 63\% das entrevistadas informaram já ter sido vítimas de violência, sendo que em 38\% dos casos o agressor era o companheiro íntimo. A violência mais recorrente relatada pelas participantes foi a psicológica (46\%). As pesquisadoras identificaram, ainda, que existe uma correlação entre os níveis de escolaridade e 
aceitação de determinadas formas de violência, assemelhando-se aos resultados obtidos em investigações realizadas em outros contextos:

Em relação ao grau de escolaridade das mulheres vitimadas, confirma-se, também, através de dados apresentados em uma pesquisa realizada em Fortaleza (CE), a permanência por um período curto na escola delimita o baixo nível de escolaridade, favorecendo, assim, a situação de violência no grupo investigado, visto que mulheres mais esclarecidas tendem a ter menor grau de tolerância à situação. Acrescenta-se, ainda, que as mulheres vítimas de violência estudaram em média seis anos, mesmo constatando-se afirmações de que a violência ocorre com mulheres de todos os níveis educacionais (ALBUQUERQUE et al., 2013, p. 389).

Os achados supracitados robustecem a defesa dos proponentes deste artigo: as instituições educativas, incluindo as de educação profissional técnica de nível médio, devem se comprometer com ações relativas à manifestação e enfrentamento da violência (SILVA et al., 2016). Ao abordar este tema nos espaços educativos, mulheres podem desenvolver recursos internos para reconhecerem situações de violação, bem como poderão acessar equipamentos sociais que as auxiliem a garantia de seus direitos (RAMOS; OLTRAMARI, 2010).

Em uma pesquisa realizada por Silva, Coelho e Njaine (2014), que investigou os motivos da violência contra mulher praticada pelos cônjuges, a partir dos depoimentos tanto de vítimas quanto de agressores, revelou-se que os homens culpam as mulheres por serem agredidas, minimizam ou negam a violência cometida contra suas parceiras, desqualificam a mulher e se colocam como vítimas, dizendo que se trata de uma tentativa de prejudicá-los.

Silva e Mendes (2015) realizaram uma pesquisa com um grupo de professoras de uma escola pública. Entre as participantes, 20\% disseram ser inaceitável a esposa ganhar mais que o marido. Esses resultados mostram como a lógica machista está imposta e é pouco questionada, inclusive, nos diversos contextos educativos. É papel das unidades educacionais levantar essa reflexão, porém, vê-se que educadores de diversos níveis de ensino, incluindo unidades educacionais de ensino técnico e profissionalizante, também reproduzem em seus discursos essa lógica perversa e assimétrica.

O levantamento bibliográfico realizado por Medeiros e Rodrigues (2016) revelou que, apesar de uma crescente discussão sobre a desigualdade dos gêneros na sociedade, as concepções patriarcais que inferiorizam as mulheres estão longe de serem desconstruídas. A instituição educacional que segundo os autores, deveria ser um lugar propício para propor reflexões acerca do tema, atribui comportamentos predeterminados às crianças. As práticas docentes determinam condutas que devem ser exclusivas de meninos ou meninas. Os autores supracitados relatam que um dos elementos favoráveis para a desconstrução da lógica machista reproduzida seria a formação dos educadores, trazendo uma reflexão crítica sobre o sexismo. 
Todavia, ao que parece, unidades educacionais de diferentes níveis pregam o machismo, perpetuam esse pensamento e não rompem essa lógica. Em outras palavras, pode-se afirmar que as concepções de alguns educadores de diferentes níveis de ensino corroboram a manutenção das desigualdades de gênero na sociedade. Este, sem sombra de dúvidas, deve ser outro assunto amplamente difundido em instituições de nível técnico e profissionalizante.

As violências que ocorrem no âmbito familiar são, muitas vezes, aceitáveis pela sociedade, inclusive por educadores. O imaginário da família sagrada e do espaço doméstico como asilo inviolável, respectivamente difundido por preceitos religiosos e por discursos jurídicos, dificulta a identificação da violência e a elaboração de estratégias de rompimento com essas práticas em contextos educativos, inclusive em instituições de nível técnico e profissionalizante.

A partir do Gráfico 3, constatou-se que alguns funcionários possuem concepções que demonstram aceitação da violência. Dos 76 indivíduos que participaram da pesquisa, 13 tiveram a média de resposta na linha de corte central estabelecida $(2,5)$ ou acima desta, o que corresponde a $17 \%$ dos participantes. Isto significa que para boa parte dos educadores, há níveis de aceitação de violência preocupantes, os quais requerem o desenvolvimento de ações de formação continuada para minimizar esses equívocos conceituais.

\section{Gráfico 3 - Indicadores de aceitação da violência por participante}

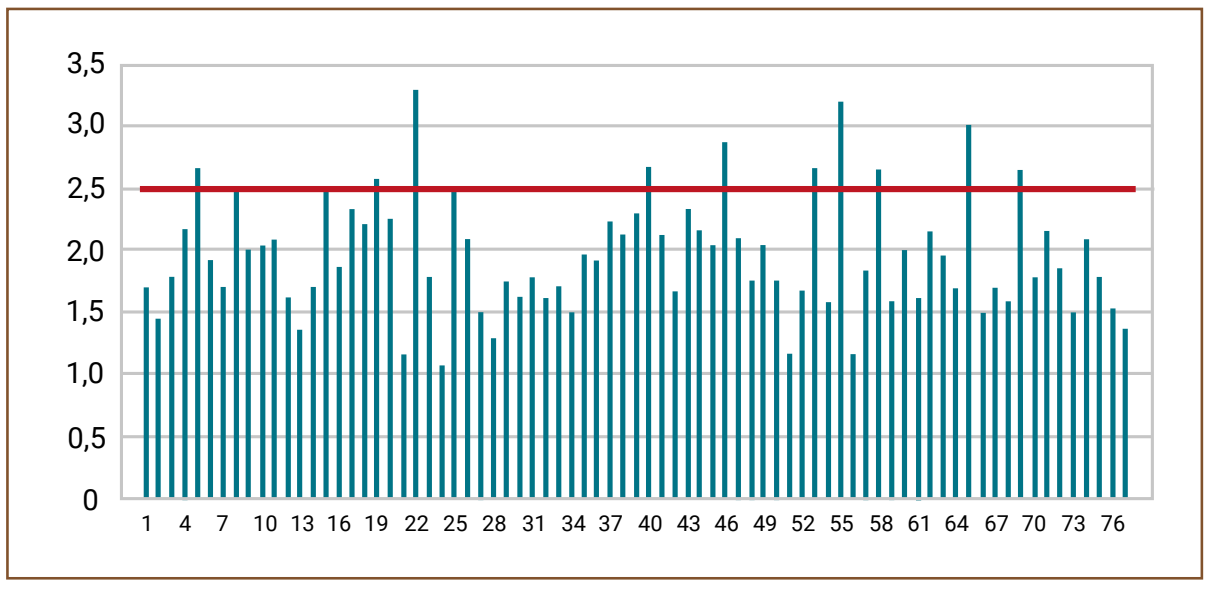

Fonte: Elaborado pelos autores.

Propagar valores como respeito, igualdade, diversidade, cultura de paz e pertencimento deve ser uma das missões das instituições educacionais. Investir em novos comportamentos, como os pró-sociais e solidários, auxiliam esse processo (WILLIANS; STELKO-PEREIRA, 2013). Nesse sentido, como já dito, o educador tem um papel fundamental, pois sua visão de mundo irá refletir de forma direta no enfrentamento das múltiplas formas de manifestação da violência. 
As instituições que ofertam os cursos de educação profissional técnica de nível médio devem extrapolar formas de educação meramente instrumental. Devem privilegiar aspectos mais amplos da formação humana, do convívio com a diferença e do estabelecimento de relações menos hierárquicas. Todavia, é basilar que os educadores e profissionais que atuam nesses contextos educativos tenham clareza de sua função social e não colaborem na reprodução de discursos e na perpetuação de práticas que nutram relações de violência na sociedade.

\subsection{Adultocentrismo e a violação dos direitos da criança e do adolescente}

Em relação aos itens que tiveram a média mais baixa (geralmente, abaixo de 1,5), ou seja, os quais mostraram que os participantes concordavam com menos veemência nas afırmativas, verificou-se que isso ocorreu quando a palavra "violência" não aparecia de forma explícita no item. Isso pode significar que a manifestação de violências mais sutis, que muitas vezes não são nomeadas pelo senso comum como violência, por exemplo, em situação de violência psicológica, são negligenciadas por educadores.

\section{Evidencia-se \\ a necessidade \\ de uma ampla \\ discussão sobre as \\ múltiplas formas \\ de violência}

Assim, evidencia-se a necessidade de uma ampla discussão sobre as múltiplas formas de violência que ocorrem cotidianamente, sobretudo nos espaços intrafamiliares e institucionais, mas que passam despercebidas pelos educadores. A violência contemporânea extrapola, em muito, agressões físicas e as formas consideradas mais explicitas de violação de direitos. Os educadores de ensino médio e profissionalizante devem compreender que as assimetrias relacionais são prejudiciais às pessoas e devem ser enfrentadas no âmbito educacional.

A média total das categorias analisadas (apresentadas na Tabela 1) ficou próxima a 2 pontos (como já dito, em uma escala que poderia varia de 2 a 5 pontos), ou seja, em média, os respondentes discordam das afirmações. Porém, analisando os fatores isoladamente, há um índice ligeiramente maior na categoria "violência contra criança e adolescente e bullying", seguido da violência contra mulher e violência policial (ver Gráfico 4). O fator que apresentou média mais rebaixada é a categoria "naturalização da violência". Todavia, reconhece-se que este é um fenômeno que se apresenta nas demais categorias, portanto, imbricado em todos os outros fatores do instrumento utilizado.

Assim, constatou-se que a violência mais tolerada pelos educadores de cursos técnicos de ensino médio e profissionalizante é aquela praticada contra crianças e adolescentes e as manifestações do bullying, tidas muitas vezes por brincadeiras que não causam danos à pessoa (CROCHÍK, 2012; RAUBER, 2016). 
Gráfico 4 - Média das respostas a partir das categorias da violência

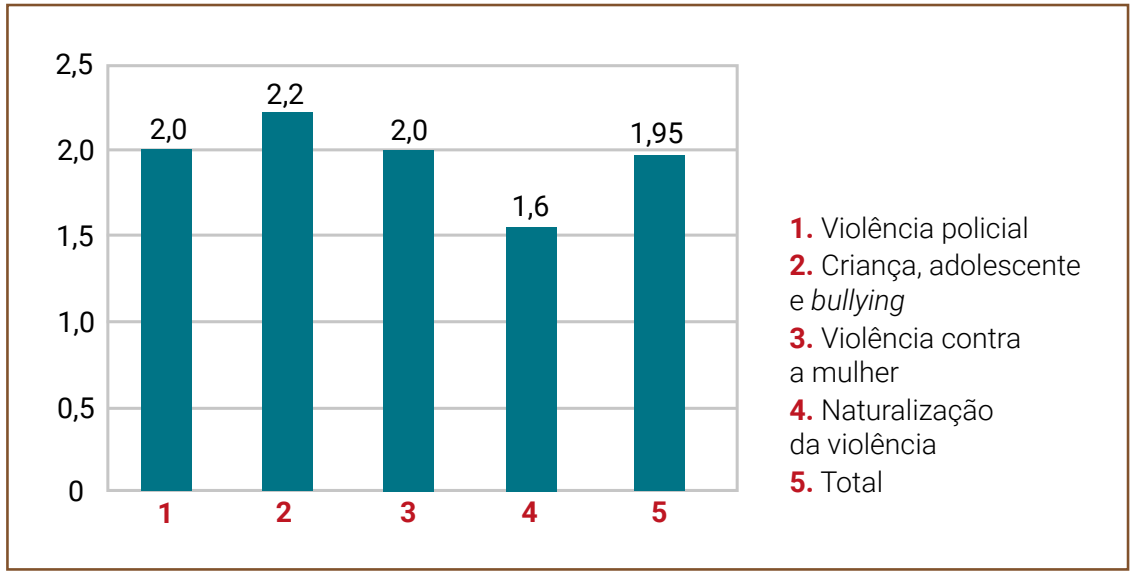

Fonte: Elaborado pelos autores.

A partir de uma análise mais aprofundada das respostas obtidas nos itens relativos aos níveis de concordância sobre a violência contra crianças e adolescentes, constatou-se que $34 \%$ dos respondentes (181 respostas) assinalaram as alternativas "não concordo, mas também não concordo", "concordo" e "concordo plenamente". Isto significa que boa parte dos educadores, de alguma forma, toleram ou justificam a ocorrência da violência contra crianças e adolescentes, tendo em vista que todos os itens que compunham essa categoria traziam, de alguma maneira, formas de violação dos direitos dessa população.

Argumentos como "a criança deve apanhar para aprender", "uma pessoa só chega onde está porque levou algumas palmadas" e "os pais devem decidir o modo como corrigem seus filhos" ainda estão presentes no imaginário dos educadores. Essa realidade impede o enfrentamento da violência contra a população supracitada e ganha contornos mais fortes, na medida em que prevalece o discurso do especialista. Em outras palavras, a violência seria justificada socialmente, pois até mesmo educadores argumentam favoravelmente à sua manutenção.

Além disso, chamaram atenção os itens que se referiam ao bullying, o qual, de acordo com alguns participantes, não existe ou se trata de brincadeiras que "nunca mataram ninguém". Na percepção de parte dos educadores, a dimensão desse fenômeno - considerado um tema de desafio para a saúde pública -, não tomou proporções alarmantes e é, de certa forma, banalizada.

De maneira similar, é possível verificar esse fenômeno na pesquisa de Lamas, Freitas e Barbosa (2013), que investigou a prevalência do bullying e a relação entre professor-aluno em três estados da Região Sudeste do Brasil, a partir de dados coletados com crianças e adolescentes do $4^{\circ}$ ao $9^{\circ}$ ano do ensino fundamental. Os resultados mostram que $18,5 \%$ dos estudantes foram alvo de bullying e $33,3 \%$ dos episódios ocorreram dentro da sala de aula. Os autores chegaram à conclusão de que a percepção do relacionamento dos agressores com seus professores foi mais 
negativa do que a relação das vítimas e, conforme maior a série, menos o professor interfere na situação de bullying. Por hipótese, no nível Médio e Técnico Profissionalizante, pode-se inferir que a interferência dos educadores nessas situações é ainda menor. Estudos sobre esse tema podem ajudar na compreensão mais assertiva sobre o assunto.

Além de danos imediatos, alguns trabalhos indicam que o bullying pode causar transtornos em longo prazo para as vítimas, como o Transtorno de Estresse Pós-traumático (ALBUQUERQUE; WILLIAMS; D’AFFONSECA, 2013), bem como depressão e ansiedade nos agressores (BINSFELD; LISBOA, 2010). Esses dados mostram que, além de prejudicar as vítimas de bullying, esse fenômeno também traz impactos negativos para os agressores. Dada a severidade do fenômeno, estudos e modelos interventivos sobre bullying devem fazer parte do projeto pedagógico de instituições de cursos técnicos de nível médio e profissionalizante.

A disseminação das "piadas" e "brincadeirinhas [aparentemente] inocentes", como sendo "normais" e parte da convivência humana pode mascarar manifestações de violências que se perpetuam em instituições de cursos técnicos de nível médio e profissionalizante. Nesses casos, não há respeito às diferenças, muito pelo contrário, são utilizadas com o propósito de machucar o outro, por intermédio do estabelecimento de correlação de força, poder e subalternidade.

\section{Gráfico 5 - Dados relativos à categoria "Violência conta criança e adolescente e bullying"}

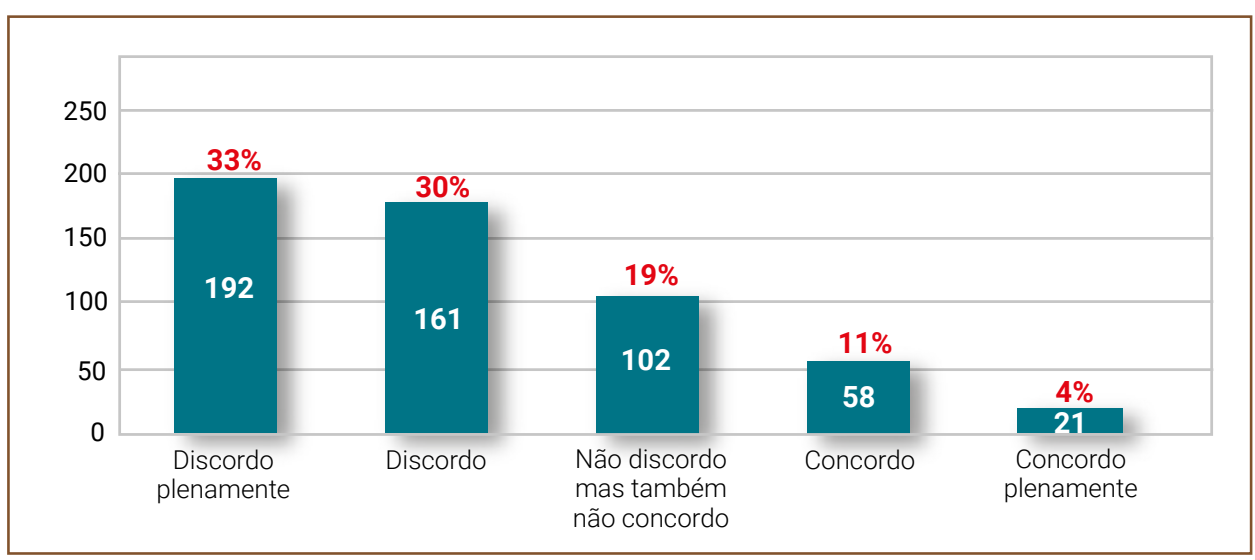

Fonte: Elaborado pelos autores.

A aceitação da violação dos direitos da criança e do adolescente, bem como a recorrência do bullying em instituições educativas, incluindo nos cursos técnicos de nível médio e profissionalizante, tem suas bases explicativas no modelo de sociedade adultocêntrica (MARANHÃO et al., 2014; RUSSO et al., 2014). Sua marca principal é a desconsideração dos direitos das populações infantojuvenis, que deixam de ter suas particularidades reconhecidas e são subjugadas a partir de relações assimétricas estabelecidas com indivíduos em estágios de desenvolvimento psicossociais mais avançados. 
Na medida em que educadores naturalizam as formas de violência que existem contra crianças e adolescentes, há um reforço social de práticas autoritárias e desrespeitosas em relação aos direitos dessa população. Todos os níveis de ensino, incluindo instituições que oferecem cursos técnicos de nível médio e profissionalizante, devem promover ações de enfrentamento às formas de violência existentes. Sem dúvida, a percepções que os profissionais têm sobre esse conceito e seus desdobramentos são fundamentais para o combate das mazelas sociais e dos mecanismos opressores que são inerentes à violação de direitos de diferentes populações.

\section{Limitações do estudo e implicações práticas}

Reconhecer as limitações do estudo é importante, pois permite que outros pesquisadores interessados no tema possam dar continuidade às investigações dessa natureza por meio de estratégias mais diversificadas e a partir do corpo de conhecimento possibilitado pela presente pesquisa.

As discussões ao longo do manuscrito enfatizaram as respostas obtidas junto aos participantes a partir dos itens relativos a expressões da violência contra crianças, adolescentes e mulheres. Isso porque ficou evidente que os educadores tenderam a aceitar, com mais tenacidade, formas de violação dos direitos destes grupos. Todavia, as demais expressões de violência (policial e o bullying) não devem ser menosprezadas, tanto no que diz respeito a pesquisas futuras quanto aos programas de formação continuada acerca da violência voltados para professores de educação profissional técnica de nível médio.

Ressalta-se que, embora de natureza quantitativa, os achados desta investigação não podem ser replicados de maneira descontextualizada a outras realidades institucionais. Por se tratar de um estudo de caso, cuja unidade de análise é uma instituição, os resultados não permitem generalizações demasiadas. Todavia, as constatações obtidas permitem que a instituição problematize, de maneira fundamentada, as concepções de violência que podem persistir no imaginário de alguns educadores de cursos técnicos de nível médio e profissionalizante.

Também é válido mencionar a importância da condução de estudos de natureza qualitativa sobre o fenômeno da violência a partir das concepções de educadores. Por não se tratar do objetivo da presente investigação, não foi possível estabelecer relações conceituais ou hipotéticas que explicassem, do ponto de vista subjetivo dos participantes, determinadas formas de compreender as violências. Assim, sugere-se a realização de outras investigações, com recorte qualitativo, para analisar os sentidos pessoais e significados sociais atribuídos à violência por educadores. Estudos mistos (mixed-methods) certamente se configuram como modelos adequados e profícuos para essa empreitada. 
Em termos das aplicações práticas, destaca-se o caráter inédito desta investigação em averiguar questões relativas à violência no contexto de educação de cursos de nível técnico médio e profissionalizante. Embora muitas pesquisas sobre o papel das instituições educacionais no combate e prevenção à violência tenham sido realizadas nos últimos anos, é praticamente inexistente essa análise aplicada à realidade de cursos técnicos de nível médio e profissionalizante.

Desse modo, espera-se que esta investigação aponte para o início de pesquisas dessa natureza no nível de ensino supracitado e enseje novos estudos sobre a temática da violência. Como defendido desde o início deste artigo, os cursos técnicos de nível médio e profissionalizante não devem assumir, simplesmente, objetivos didático-pedagógicos e instrumentais da educação. Temas transversais, incluindo a violência, devem, necessariamente, compor o projeto pedagógico dessas unidades educacionais.

\section{Considerações finais}

A investigação revelou que parte dos educadores atuantes na instituição que oferece cursos técnicos de nível médio e profissionalizante possui concepções de violência naturalizadas, que podem implicar a aceitação de sua ocorrência ou a falta de análise crítica desse fenômeno. Os dados mais alarmantes referem-se à manifestação de violências que ocorrem no contexto intrafamiliar, em especial, voltadas para crianças, adolescentes e mulheres.

Desse modo, sugere-se, a partir das constatações empíricas desta investigação, que sejam ofertados espaços de formação continuada em instituições de ensino de nível médio e profissionalizante, os quais auxiliem os profissionais a reconhecerem manifestações da violência, mesmo aquelas que ocorrem de maneira sutil e passam desapercebidas no cotidiano. Advoga-se, portanto, pela implantação de ações pedagógicas que extrapolem o ensino técnico e profissionalizante do ponto de vista da formação profissional.

O fenômeno da violência atinge diversos setores da sociedade e, em especial, alguns segmentos que se mostram mais fragilizados. Negligenciar essas constatações pode implicar uma cultura despolitizada e alheia às dinâmicas sociais que exigem articulação social para o combate da violação dos direitos conquistados historicamente na sociedade brasileira.

\section{Notas}

${ }^{1}$ Agradecemos à Gabrielle Cristina, docente da Unoeste, pelo auxílio nas análises estatísticas apresentadas no decorrer deste manuscrito.

2 Para mais informações sobre o Programa Escola que Protege, acesse o link http:// portal.mec.gov.br/projeto-escola-que-protege/escola-que-protege - Acesso em: 29 maio 2018. 


\section{Referências}

ABRAMOVAY, Miriam; RUA, Maria das Graças. Violências nas escolas. Brasília, DF: Unesco, 2002.

ADORNO, Sérgio. Crime e violência na sociedade brasileira contemporânea. Jornal PSI, São Paulo, n. 132, p. 7-8, abr./jun. 2002.

ALBUQUERQUE, Josefa Barros Cavalcanti et al. Violência doméstica: características sociodemográficas de mulheres cadastradas em uma Unidade de Saúde da Família. Revista Eletrônica de Enfermagem, Goiânia, v. 15, n. 2, p. $382-$ 390, abr./jun. 2013.

ALBUQUERQUE, Paloma Pegolo; WILLIAMS, Lúcia Cavalcanti de Albuquerque; D'AFFONSECA, Sabrina Mazo. Long term effects of bullying and posttraumatic stress disorder: a literature review. Psicologia: teoria e pesquisa, Brasília, DF, v. 29, n. 1, p. 91-98, jan./mar. 2013.

ASSIS, Luana Rambo; NASCIMENTO, Lizandra Andrade. Serviço social e violência: caminho na luta pela garantia de direitos humanos. Revista Gestão e Desenvolvimento em Contexto, Cruz Alta, v. 1, n. 1, p. 50-57, jan./dez. 2013.

BARUFALDI, Laura Augusta et al. Violência de gênero: comparação da mortalidade por agressão em mulheres com e sem notificação prévia de violência. Ciência e Saúde Coletiva, Rio de Janeiro, v. 22, n. 9, p. 2929-2938, set. 2017.

BINSFELD, Adriana Raquel; LISBOA, Carolina Saraiva de Macedo. Bullying: um estudo sobre papéis sociais, ansiedade e depressão no contexto escolar do sul do Brasil. Interpersona, Vitória, v. 4, n. 1, p. 74-105, jan./jun. 2010.

BISCEGLI, Terezinha Soares et al. Violência doméstica contra crianças: nível de conhecimento dos pais de crianças em escolas pública e privada. Revista Paulista de Pediatria, São Paulo, v. 26, n. 4, p. 365-371, out./nov. 2008.

BRASIL. Congresso. Câmara dos Deputados. LDB: lei de diretrizes e bases educação nacional.11. ed. Brasília, DF: Edições Câmara, 2015.

BRASIL. Ministério da Saúde. Impacto da violência na saúde das crianças e adolescentes: prevenção de violências e promoção da cultura de paz. Brasília, DF, 2009. 
BRASIL. Projeto de Lei n. 7672/10. Altera a Lei 8.079, de 13 de julho de 1990, que dispõe sobre o estatuto da criança e do adolescente. Brasília, DF: Câmara dos Deputados, 2011.

CARDIA, Nancy. Pesquisa sobre atitudes, normas culturais e valores em relação a violência em 10 capitais brasileiras. Brasília, DF: Ministério da Justiça, Secretaria Nacional dos Direitos Humanos, 1999.

CHAUÍ, Marilena. Ética, política e violência. In: CAMACHO, Thimoteo (Ed.). Ensaios sobre violência. Vitória: Edufes, 2003. p. 39-59.

COCCO, Marta et al. Violência contra crianças: dimensões apreendidas nas falas de professoras de educação infantil e a articulação com o setor saúde. Revista Mineira de Enfermagem, Belo Horizonte, v. 14, n. 4, p. 457-458, jan./mar. 2010.

CROCHIK, José Leon. Fatores psicológicos e sociais associados ao bullying. Revista Psicologia Política, São Paulo, v. 12, n. 24, p. 211-229, ago. 2012.

D’AFFONSECA, Sabrina Mazo; PRIOLO FILHO, Sidnei Rinaldo; WILLIAMS, Lúcia Cavalcanti de Albuquerque. Intervenção psicoterapêutica com famílias em situação de violência: relato de atividade de extensão. Revista Brasileira de Extensão Universitária, Chapecó, v. 7, n. 1, p. 43-49, jan./jun. 2016.

FALEIROS, Vicente de Paula. Redes de exploração e abuso sexual e redes de proteção. In: CONGRESSO BRASILEIRO DE ASSISTENTES SOCIAIS, 9, 1998, Goiânia, Anais. Goiânia: Conselho Federal de Serviço Social, 1998. v. 1, p. 267-271.

FALEIROS, Vicente de Paula; FALEIROS, Eva Silveira. Escola que protege: enfrentando a violência contra crianças e adolescentes. Brasília, DF: Ministério da Educação, 2007.

FELTRIN, Lohana Pinheiro et al. Lei da palmada: reflexões e implicações psicojurídicas. Revista Eletrônica do Curso de Direito da UFSM, Santa Maria, v.8, n. 1, p.184-203, maio/ago. 2013.

GUIMARÃES, Maisa Campos; PEDROZA, Regina Lúcia Sucupira. Violência contra a mulher: problematizando definições teóricas, filosóficas e jurídicas. Psicologia \& Sociedade, Belo Horizonte, v. 27, n. 2, p. 256-266, maio/ago. 2015.

HEREM, Claudenice Matos. Perfil e formação de do professor de educação profissional técnica. São Paulo: Ed. Senac São Paulo, 2009. 
HILDEBRAND, Natália Amaral et al. Violência doméstica e risco para problemas de saúde mental em crianças e adolescentes. Psicologia: reflexão e crítica, Porto Alegre, v. 28, n. 2, p. 213-221, jan./jun. 2015.

LAMAS, Karen Cristina Alves; FREITAS, Eduarda Rezende; BARBOSA, Altemir José Gonçalves. Bullying e relação professor-aluno: percepções de estudantes do ensino fundamental. Psico, Porto Alegre, v. 44, n. 2, p. 263-272, abr./jun. 2013.

MACHADO, Juliana Costa et al. Violência intrafamiliar e as estratégias de atuação da equipe de Saúde da Família.Saúde e Sociedade, São Paulo, v. 23, n. 3, p.828840, jul./set. 2014.

MARANHÃO, Joyce Hilário et al. Violência, risco e proteção em estudantes de escola pública. Fractal: revista de psicologia, Niterói, v. 26, n. 2, p. 429-444, maio/ ago. 2014.

MARTÍN-BARÓ, Ignacio. La familia, puerto y carcel para la mujer salvadoreña. Revista de Psicología de El Salvador, San Salvador, v. 9, n. 37, p. 265-277, 1990.

MARTÍN-BARÓ, Ignacio. Poder, ideologia y violência. Madrid: Trotta, 2003.

MEDEIROS, Tâmara Duarte; RODRIGUES, Hermano de França. Discursos sexistas na escola: feminismo e estudos de gênero. In: CONGRESSO NACIONAL DE EDUCAÇÃO (CONEDU), 3, 2016. Natal. Anais eletrônicos. Natal: Realize, 2016.

MINAYO, Maria Cecília de Souza. Conceitos, teorias e tipologias de violência: a violência faz mal à saúde. In: NJAINE, Kathie; ASSIS, Simone Gonçalvez; CONSTANTINO, Patrícia (Org.). Impactos da violência na saúde. Rio de Janeiro: Ed. Fiocruz, 2009. p. 21-42.

MOREIRA, Ana Paula Gomes; GUZZO, Raquel Souza Lobo. Violence and prevention in school: the possibilities of liberation psychology. Psicologia e Sociedade, Belo Horizonte, v. 29, n. 1, mar. 2017. Disponível em: <http://www.scielo.br/pdf/psoc/ v29/1807-0310-psoc-29-e141683.pdf>. Acesso em: jul. 2018.

MORIN, Edgar. A cabeça bem-feita: repensar a reforma, reformar o pensamento. 8. ed. Rio de Janeiro: Bertrand Brasil, 2001.

MOURA, Leides Barroso Azevedo; OLIVEIRA, Cesar; VASCONCELOS, Ana Maria Nogales. Violências e juventude em um território da área metropolitana de Brasília, Brasil: uma abordagem socioespacial. Ciência e Saúde Coletiva, Rio de Janeiro, v. 20, n. 11, p. 3395-3405, nov. 2015. 
NORONHA, Luciana Machado. Educação integral e concepções de violência na visão de monitores do Programa Mais Educação. 2013.Monografia

(Especialização em Educação) - Faculdade de Educação, Universidade Federal do Rio Grande do Sul, Porto Alegre, 2013.

PATIAS, Naiana Dapieve; SIQUEIRA, Aline Cardoso; DIAS, Ana Cristina Garcia. Práticas educativas e intervenção com pais: a educação como proteção ao desenvolvimento dos filhos. Mudanças: psicologia da saúde, São Paulo, v. 21, n. 1, p. 29-40, jan./jun. 2013.

PEREIRA, Henrique Manuel; VIEIRA, Maria Cristina Vieira. Entrevista: pela educação, com António Nóvoa. Saber (e) Educar, Porto, v. 11, p. 111-126, jan./ dez. 2016.

PEREIRA, Paula Celso; WILLIAMS, Lúcia Cavalcanti Albuquerque. A concepção de educadores sobre violência doméstica e desempenho escolar. Revista Semestral da Associação Brasileira de Psicologia Escolar e Educacional (ABRAPEE), São Paulo, v. 12, n. 1, p. 139-152, jan./jun. 2008.

RAMOS, Maria Eduarda; OLTRAMARI, Leandro Castro. Atividade reflexiva com mulheres que sofreram violência doméstica. Psicologia: ciência e profissão, Brasília, DF, v. 30, n. 2, p. 418-427, abr./jun. 2010.

RATES, Susana Maria Moreira et al. Violência infantil: uma análise das notificações compulsórias, Brasil 2011. Ciência e Saúde Coletiva, Rio de Janeiro, v. 20, n. 3, p. 655-665, mar. 2015.

RAUBER, Clair. Bullying: a violência no cotidiano da escola. Revista Eventos Pedagógicos, v. 7, n. 2, p. 316-329, jun./jul. 2016.

RUSSO, Gláucio et al. Quando a realidade cala: violência psicológica intrafamiliar contra crianças e adolescentes em Mossoró-RN. Temporalis, Brasília, DF, v. 14, n. 27, p. 159-180, jan./jun. 2014.

SANTOS, Adriana Ribeiro dos; MARIN, Angela Helena; CASTOLDI, Luciana.

Percepção de mães e adolescentes sobre a violência intrafamiliar por meio da construção do genograma. Contextos Clínicos, São Leopoldo, v. 6, n. 2, p. 174-184, jul./dez. 2013.

SANTOS, Jean Mac Cole Tavares; RODRIGUES, Paula Janaina Meneses. O diálogo como possibilidade de mediação da violência na escola. Práxis Educativa, Ponta Grossa, v. 8, n. 1, p. 273-294, jan./jun. 2013. 
SANTOS, José Vicente Tavares; TEIXEIRA, Alex Niche; RUSSO, Maurício. Violência e cidadania: práticas sociológicas e compromissos sociais. Porto Alegre: Ed. da UFRGS, 2011.

SANTOS, Jurandir. Educação: desafios da atualidade. São Carlos: Compacta Ed., 2012.

SANTOS, Rita de Cássia Ferreira. Violência sexual e a formação de educadores: uma proposta de intervenção. 2011. Dissertação (Mestrado em Educação) Faculdade de Ciências e Tecnologia, UNESP, Presidente Prudente, 2011.

SERAPIONI, Mauro. Métodos qualitativos e quantitativos na pesquisa social em saúde: algumas estratégias para integração. Ciência e Saúde Coletiva, Rio de Janeiro, v. 5, n. 1, p. 197-192, jan./jun. 2000.

SEVERINO, Antônio Joaquim. Metodologia do trabalho científico. 23. ed. São Paulo: Cortez, 2007.

SILVA, Anne Caroline Luz Grüdter; COELHO, Elza Berger Salema; NJAINE, Kathie. Violência conjugal: as controvérsias no relato dos parceiros íntimos em inquéritos policiais. Ciência e Saúde Coletiva, Rio de Janeiro, v. 19, n. 4, p. 1255-1262, abr.2014.

SILVA, Maví Consuelo; MENDES, Olenir Mender. As marcas do machismo no cotidiano escolar. Caderno Espaço Feminino, Uberlândia, v. 28, n. 1, p. 90-99, jan./ jun. 2015.

SILVA, Patrick Leonardo Nogueira et al. Práticas educativas sobre violência contra a mulher na formação de universitários. Revista Bioética, Brasília, DF, v. 24, n. 2, p. 276-285, maio/ago. 2016.

SOARES, Michelle Beltrão; MACHADO, Laêda Bezerra. Violência contra o professor nas representações sociais de docentes. Perspectiva, Florianópolis, v. 32, n. 1, 333-354, jan./abr. 2014.

TIMM, Flávia Bascuñán; PEREIRA, Ondina Pena; GONTIJO, Daniela Cabral. Psicologia, violência contra mulheres e feminismo: em defesa de uma clínica política. Revista Psicologia Política, São Paulo, v. 11, n. 22, p. 247-259, dez. 2011.

VIAMONTE, Perola Fatima Simpson. Ensino profissionalizante e ensino médio: novas análises a partir da LDB 9394/96. Educação em Perspectiva, Viçosa, v. 2, n. 1, p. 28-57, jan./jun. 2011. 
WILLIAMS, Lúcia Cavalcanti de Albuquerque; MALDONADO, Daniela Patrícia Ado; COSTA, Ricardo. Uma vida livre de violência. São Carlos: Padovani, 2008.

WILLIAMS, Lúcia Cavalcanti de Albuquerque; STELKO-PEREIRA, Ana Carina. (Org.). Violência nota zero: como aprimorar as relações na escola. São Carlos: EdUFSCar, 2013.

YIN, Robert K. Estudo de caso: Planejamento e métodos. 4. ed. Porto Alegre: Bookman, 2010. 